\title{
Perceptions of the Fiscal Challenges Facing Athletic Departments of Historically Black Colleges and Universities
}

\author{
Kelly Elliott ${ }^{1}$ and Timothy Kellison ${ }^{2}$ \\ ${ }^{1}$ Coastal Carolina University, ${ }^{2}$ Georgia State University
}

\begin{abstract}
Research has shown the athletic departments of historically black colleges and universities (HBCUs) do not generate significant revenue. The financial struggle facing HBCU athletic departments can be explained using resource dependency theory. Specifically, as HBCUs are the most under-resourced member institutions of the National Collegiate Athletic Association (NCAA), the numbers demonstrate how these institutions lack sufficient funding to invest in their programs. The purpose of this study is to explore the fiscal challenges facing HBCU athletic departments. To gather this information, two different groups of participants were interviewed to obtain an independent and insider perspective of the challenges. Phenomenology was the methodological approach for this study as each participant had the opportunity to discuss their unique view of the current financial state of HBCU athletic departments. Participants took part in semi-structured interviews framed around fiscal challenges. This study contributes to the growing body of literature addressing HBCU athletics by providing an exploration of current fiscal challenges facing the institutions.
\end{abstract}

Keywords: HBCU, finances, collegiate athletics, administration, NCAA

Historically black colleges and universities (HBCU) administrators have noted funding university athletic programs is difficult due to participation costs and small enrollment (Arnett, 2014; Savage, 2017). Limited funding stems from HBCUs' commitment to serving low-income students and small endowments, leading to low operating costs (Gasman, 2009). With the financial challenges facing HBCUs, it is crucial to explore how these challenges impact athletic programs on campus. Without this information, HBCU administrators may not be able to make optimal decisions regarding their institutions' finances. An understanding of this financial picture is paramount, as smaller operating costs lead to less available resources for athletic departments. Recent research has found that HBCUs spend less annually on operating expenses, head coach salaries, recruiting, and athletic aid, when compared to their peer institutions (Elliott, Kellison, \& Cianfrone, 2019). The current financial picture indicates that research is needed to have a better understanding of the fiscal challenges faced by HBCU athletic departments. Therefore, the purpose of this study is to explore the fiscal challenges facing $\mathrm{HBCU}$ athletic departments. 
In previous studies involving HBCU athletics, researchers have looked into the current administrative, coach, and college-athlete perspectives of HBCU athletic departments and programs. These studies lay the groundwork for understanding the fiscal challenges facing HBCU athletic departments. A discussion of this previous literature is presented below.

\section{Literature Review}

\section{College Athlete Success at HBCUs}

Research indicates that Black students at HBCUs find more success than those at historically white institutions of higher education (HWIHEs) (Cooper \& Dougherty, 2015; Cooper \& Hawkins, 2012, 2014). Specifically, Cooper and Hawkins (2014) interviewed male college athlete transfers from HWIHEs to HBCUs and found the college athletes reported feeling like an outcast while on campus at a HWIHE, but felt they had more support on campus at an HBCU. Black college athletes on HBCU campuses consistently report feeling supported, especially from their professors (Cooper \& Dougherty, 2015; Cooper \& Hawkins, 2012, 2014; Cooper, Porter, \& Davis, 2017). Black college athletes at HBCUs have also reported feeling more satisfied socially on campus compared to Black college athletes at HWIHEs (Cooper \& Dougherty, 2015). From a college-athlete perspective, research supports the need for HBCUs, as the institutions fill a necessary component for college athletes achieving academic and athletic success. Despite this value, funding the athletic experience at HBCUs is an area with minimal critical research.

The attractiveness of HBCUs has also been studied, as these institutions are continuously falling to the bottom of the U.S. News and World Report's "America's Best Colleges" rankings. However, research from Jones (2015) suggests there is no connection between rankings and the number of applications received by HBCUs. The research reported by Jones (2015) indicates that a different type of student might apply to an HBCU, including those who will be applying to an array of institutions, which include multiple HBCUs in addition to non-HBCUs. With the competition for students, HBCU coaches might find recruiting a challenge as previous research indicates HBCUs have limited funding available for recruiting purposes (Elliott \& Kellison, 2018). With the competitive nature of recruiting in college athletics, the finances available for a coach to travel to a recruit, or bring a recruit to campus, could impact their overall success. Although HBCU athletics has been studied from the college-athlete perspective, it is also important to explore the perspectives of college coaches and administrators to acquire a better understanding of the fiscal challenges facing HBCU athletic departments.

\section{HBCU Coaches and Administrators}

Previous research has identified possible stressors facing HBCU coaches that might lead to the reported underrepresentation of Black and Latinx head coaches at the helm of college football programs (Bozeman \& Fay, 2013). These possible stressors include the multiple responsibilities HBCU coaches have above and beyond coach- 
ing duties (Robbins, Gilbert, \& Clifton, 2015) and the pressure to play in guarantee games, resulting in poor overall records for head coaches (Auerbach, 2016). Despite the revenue reported from HBCUs participating in guarantee games, research from Lillig (2009) suggests the contracts for HBCUs might not prove to be as lucrative.

From an athletic administrator's perspective, athletic directors at HBCUs are younger, have more graduate degrees in comparison to their peers, have more coaching/teaching responsibilities, and are paid significantly less (Quarterman, 1992). Although HBCU athletic directors have more responsibilities on campus, previous research also suggests HBCUs are not hiring a marketing or external relations employee in their athletic departments to help raise funds (Jackson, Lyons, \& Gooden, 2001; Li \& Burden, 2009). An assessment of spectator responses to sponsors at an HBCU football game indicated HBCUs were not using signage to create brand awareness for sponsors in athletic venues (Elliott et al., 2018). The reported lack of external relations employees underscores the need for research to explore the current state of financial issues facing HBCUs and advocates for the attempt to address areas where improvement can help the institutions find better financial success. Previous research suggests HBCU football games are just one part of the overall social experience that surrounds HBCU athletic events (Cianfrone, Pitts, Zhang, Byrd, \& Drane, 2010). Research to help assess how HBCUs can engage their fanbase to increase revenue dollars can help offset the limited staff serving the athletic department on campus. This current research into the fiscal challenges facing HBCU athletic departments adds to the literature by providing an administrative perspective into financial challenges facing HBCU athletic departments. The next section offers a discussion of resource dependency theory as an explanation for the current financial challenges facing HBCU athletic departments.

\section{Resource Dependency, Power, and HBCUs}

Previous research has analyzed HBCU athletics using critical race theory (Cheeks \& Carter-Francique, 2015; Cooper, Cavil, \& Cheeks, 2014); however, to expand the theoretical literature in HBCU athletics, a resource dependency perspective is explained in detail below as it relates to HBCU athletics.

Salancik and Pfeffer (1977) indicated that organizations will compete for resources that are in scarce supply. In other words, the resources an organization possesses determine its overall power (Salancik \& Pfeffer, 1977). Organizations will always compete for limited resources, and there will always be competition between groups with more resources and groups with fewer resources, leading to the organization with the most resources having power. Resource dependency theory acknowledges that resources are a basis for power and organizations depend on resources. For example, Salancik and Pfeffer (1977) indicated that organizations will compete for resources that are in scarce supply, and not necessarily abundant resources. Resource dependency theory assumes three principles of the organization: (1) organizations are assumed to be partnerships that involve social exchanges formed to influence and control behavior; (2) the organization's environment contains scarce and valued resources essential to organizational survival; and (3) organizations are assumed to 
work towards acquiring control over resources that minimize their dependence on other organizations and to acquire control over resources that maximize the dependence of other organizations on themselves (Ulrich \& Barney, 1984).

From a resource dependency perspective, the resources an organization has determines its overall power. Specifically addressing HBCUs, the numbers demonstrate how these institutions do not have the funds to invest in their athletic programs. According to information obtained from the Equity in Athletics Data Analysis dataset, HBCUs are spending significantly less compared to their peer institutions on recruiting, operating, total expenses, and head coach salaries (Elliott \& Kellison, 2019). With the lack of funding, some Division I HBCU athletic administrators are debating moving to Division II where they might be more competitive on a financial level (Trahan, 2012). This reality creates imbalance, especially in the Division I category, because these institutions are securing funds from the annual March Madness basketball tournament by the team's ability to qualify. If Division I HBCUs do not have the funds to compete with fully funded Division I programs, their teams might not find success in the tournament and the institutions will not acquire access to the revenue distribution.

While it is clear that many HBCUs are facing financial difficulties, it is less clear how these issues have impacted athletic administrators' ability to manage their own department and deliver programming. As such, the purpose of this study is to explore the fiscal challenges facing HBCU athletic departments.

\section{Methods}

In this study, both an insider and an independent perspective were used to guide research. Key individuals whose knowledge and opinions may provide important insights regarding the research questions were selected (Hancock \& Algozzine, 2017). The insider perspective refers to those individuals who work at HBCUs, but have also had experience working with HWIHEs through previous work experience or NCAA committee work. Conversely, the independent perspective is represented by individuals who work with HBCUs (but are not employed at HBCUs). Concerning the latter group, this perspective may offer an unbiased assessment of HBCU athletic departments' financial opportunities and challenges. That is, individuals representing the independent perspective work with both HWIHEs and HBCUs and have an understanding not only of the issues faced by HBCUs, but also how they differ from their HWIHE peers. All participants in this study either worked at or had experience working with NCAA Division II HBCUs at the time of interviewing. The consideration of the independent perspective was based on an association-wide proposal submitted by the NCAA Board of Governors during the NCAA 2019 Convention. The proposal sponsored by the Board of Governors added five independent members to the Board, thereby increasing its size from 20 to 25 members. The rationale for this proposal was based on the fact that: 
. . major nonprofit associations typically include outside board members to provide objectivity, relevant experience, perspective, and wisdom. Board members with those qualities will provide valuable insight to the NCAA as it works towards the restoration of public confidence in college basketball and college sports in general. (2019 NCAA Convention, p. 2)

Following the importance placed by the NCAA to include outside board members who could provide a unique perspective to association membership, we employed a similar approach in this study. Attaining the perspective of an independent party who did not work at an HBCU member institution provided additional, impartial insight on financial struggles that might otherwise not have been provided by participants working on campus. This perspective could prove imperative as these participants will have experience with both HBCU and HWIHE athletic departments and can articulate any differences or similarities.

\section{Interview Guide}

To gain a better understanding of the fiscal challenges faced by HBCU athletic departments, a qualitative approach was used to explore both insider and independent views of the HBCU athletic department financial picture as it relates to fiscal challenges. The professionals selected for this study participated in semi-structured interviews to address the research questions. This method was chosen because of the exploratory nature of the research questions and the participants' expertise in matters concerning both HBCUs and HWIHEs. Additionally, semi-structured interviews offer the opportunity for the researcher to ask follow-up questions for important points made by the interviewee (Brinkmann, 2013). The qualitative findings are helpful in identifying similarities and differences that might have been overlooked in previous studies of HBCU athletic departments.

Below, the questions that guided the interview are listed. It is important to acknowledge that, at times, interviews strayed from these questions based on the responses of the participants. After an initial question that asked participants to describe their experiences working at or with both HWIHEs and HBCUs, the following questions were asked:

1. What challenges do you see facing HBCU athletic departments?

2. If challenges, what challenges differ from HWIHE athletic departments?

3. Are any of these challenges similar?

4. Have you noticed any attempt to rectify any of these challenges?

5. What do you think is the best course of action to help institutions face these challenges?

6. What would you recommend to $\mathrm{HBCU}$ athletic administrators facing these challenges?

7. Would you give the same advice to HWIHE athletic administrators? 
A phenomenological approach was employed in this study. This approach is a useful approach, as everyone looks at the world differently, and individual experiences shape the way they look at the world (Crotty, 1998). Through phenomenology, we relied on participant perspectives through interviews to provide an understanding of the differences between working with athletic departments at HWIHEs and HBCUs.

\section{Participants}

Interviews in this study were conducted with participants from two groups (i.e., insiders and independents). Each group included five participants. The first group provided an insider perspective and was composed of participants that worked at HBCUs, including athletic directors, senior-level staff, and vice presidents. The second group gave an independent perspective and included conference office employees, NCAA staff, and consultants that work with HBCUs.

\section{Table 1}

\begin{tabular}{|c|c|c|c|c|}
\hline $\begin{array}{l}\text { Participant } \\
\text { Type }\end{array}$ & Pseudonym & $\begin{array}{l}\text { Years } \\
\text { of Experience }\end{array}$ & $\begin{array}{l}\text { Highest Level } \\
\text { of Education }\end{array}$ & Working Role \\
\hline Independent & Eleanor & $4+$ & Master's Degree & Director \\
\hline Independent & Francis & $18+$ & Master's Degree & Consultant \\
\hline Independent & Penelope & $20+$ & Master's Degree & Consultant \\
\hline Independent & Olivia & $20+$ & Master's Degree & Consultant \\
\hline Independent & Theodore & $4+$ & Bachelor's Degree & Director \\
\hline Insider & Fitz & $20+$ & Master's Degree & Vice President \\
\hline Insider & Finn & $18+$ & Master's Degree & $\begin{array}{l}\text { Assistant Athletic } \\
\text { Director }\end{array}$ \\
\hline Insider & Lynn & $20+$ & Master's Degree & $\begin{array}{l}\text { Director of } \\
\text { Athletics }\end{array}$ \\
\hline Insider & Josie & $20+$ & Master's Degree & $\begin{array}{l}\text { Director of } \\
\text { Athletics }\end{array}$ \\
\hline Insider & Briel & $20+$ & Bachelor's Degree & $\begin{array}{l}\text { Associate } \\
\text { Athletic Director/ } \\
\text { Senior Woman } \\
\text { Administrator }\end{array}$ \\
\hline
\end{tabular}


The intent of an interview-based study should be to provide "the chance to look in detail at how selected people experience the world" (Brinkmann, 2013, p. 59). Thus, the more in-depth the interviews are with each participant, the fewer participants will be necessary for the study (Taylor, Bogdan, \& DeVault, 2016). The sample selected for this study represents various groups of people who work at or with HBCU athletic departments. The researchers limited the number of participants to ensure the opportunity to focus on each interview in greater depth. Purposive sampling was used to ensure the selection of key individuals whose knowledge and opinions could provide important insights regarding the research questions (Hancock \& Algozzine, 2017). Table 1 contains a description of each of the participants.

\section{Procedures}

Empirical material was collected from semi-structured interviews. The researchers obtained phone numbers to reach out to potential participants through staff directory pages on college, NCAA, and conference office websites. Interviews were conducted face-to-face when possible. However, when not possible, phone interviews were used. In total, two face-to-face interviews and eight phone interviews were completed. Face-to-face interviews can be beneficial because researchers are able to examine body language and facial expressions in addition to the dialogue of the interviewee (Brinkmann, 2013). Phone interviews limit the ability of the researcher to examine facial expressions and body language. However, Brinkmann (2013) noted that despite the additional information gathered from the face-to-face interviews, these types of interviews can be cost-prohibitive and might restrict participants to certain geographic locations that are easy for both the interviewer and interviewee to access. To ensure the inclusion of relevant and qualified participants in this study, we used phone interviews when the location of a participant prohibited face-to-face interviews. Each interview lasted approximately one hour.

\section{Collection of Empirical Material and Analysis}

Before beginning the interview, each participant reviewed an informed consent document. To conceal the identity of participants, pseudonyms for participants were used (Taylor, Bogdan, \& Devalut, 2016). Each interview was audio recorded and transcribed. The transcription followed a reconstruction transcription to "clean up" the conversation with each interviewee (Brinkmann, 2013). Both the audio recording and transcription were filed in a password-protected computer. Once transcripts were available, they were emailed to the participants to review for accuracy. Taylor et al. (2016) argues having participants review transcripts can strengthen the quality of the study and build credibility. The first author then analyzed the interviews to look for common themes as it related to the research purpose. The empirical material was coded and then sub-coded as common themes were found between participant responses. Specifically, events, actions, interactions, and emotions were compared and assigned a coding label so that they could be grouped (Brod, Tesler, \& Christiansen, 2009). The process for coding the empirical material followed a data-driven coding process. This process allowed the first author to begin the process of analysis without codes (Brinkmann, 2013). 


\section{Findings}

The research findings are organized into two different sections: those from interviews with the independent participants and those from interviews with inside participants.

\section{Independent Perspective}

In the empirical material collected from the independent participants regarding fiscal issues, two overarching themes were identified: challenges and opportunities. These and their subthemes are discussed in turn below.

\section{Challenges}

Amongst the fiscal challenges facing HBCU athletic departments, the subthemes of advancement, history, administration, global issues, and fan experience emerged. The following sections outline the findings from each of these subthemes.

Advancement. The most common subtheme involved advancement, specifically working with the office of advancement and trying to raise funds for the department of athletics. The most common issue discussed throughout the interviews was the perceived lack of alumni giving at HBCUs. It was gathered that participants believed there was a lack of involvement from alumni and that their experience was that alumni at HBCUs were not in the habit of giving back to their institutions. This discussion was consistent with previous research from Stuart (2017) addressing the lack of alumni giving at HBCUs. Olivia mentioned the following addressing alumni giving at HWIHEs:

There [are] years and years of experience of cultivating alumni relations, cultivating alumni donations, promoting the athletic department. This has been ingrained in what has been happening for a much longer period of time at [HWIHWs].

From the perspective of those working closely with HBCUs, it did not appear that there has been a lot of sustained interaction or experience working with fundraising and corporate sponsorships at HBCUs. When asked why this might be the case, participants pointed to the type of majors and graduates of HBCUs. Specifically, Penelope stated the following:

A lot of HBCUs from my perspective are educating educators. They are faithbased institutions that have alumni that are not making as much money. Wealthy white folk are able to give more because of the majors they are able to offer as opposed to educators and preachers, or at some of the [Southern Intercollegiate Athletic Conference] schools the kids grow up to be ministers or major in sociology, and therefore, have a different level of being able to give back. 
The empirical material collected shows the possible challenge HBCU athletic departments face when trying to raise money from alumni. However, there can be additional challenges on campus as athletic departments try and raise money through fundraising and campaigns.

From the independent participants' perspectives, there seemed to be an internal conflict between athletic employees and their institutional advancement offices over what donors should be tapped for athletics and what donors should be targeted for the entire institution. For example, an office of institutional advancement might identify donors who they were targeting to give to the institution's general fund. The office of institutional advancement might not want athletic departments reaching out to the same identified donors in order to avoid a sense of "double-dipping" among donors. Francis mentioned that she has heard athletic directors voice their concerns about wanting to raise money for athletics, but they were told the office of advancement did not want them raising money because the office was working on a capital campaign.

Through the interviews with participants, it can be surmised that there is a perception that HWIHEs put more emphasis on selling their product and telling their story. Penelope reasoned that there was a little bit of a historical context as to why this might be the case:

I think there was a time where people thought, "That is a white businessman. He is not going to give to an African American university." You need to dispel that because there are great stories to be told on every campus and you need to sell these to the community.

Similar to Penelope's statement regarding the historical context of HBCU fundraising in the community, the independent participants mentioned historical challenges that were possibly still causing fiscal issues for HBCU athletic departments today. Starting at the mission and purpose, participants mentioned the original mission of HBCUs was to create educational opportunities and that although some HBCUs were trying to diversify, there is still an attempt to hold onto the fact that they started as an HBCU. Additionally, when it came to attracting fans, Theodore mentioned how HBCUs historically did not have to compete for fans, but they were now facing competition:

HBCUs come from this space where at one moment we were all we had so you were naturally given that attention from your community. But as time when on, whether you can blame it on integration or access to television or whatever, folks began to see the disparity and they would look at their HBCUs and hope that we would one day match that, but it became evident that our HBCUs were not investing in the same things that [HWIHEs] were.

Beyond the dwindling fan base that Theodore mentioned is occurring at HBCUs, participants mentioned that many question whether HBCUs still provide a unique 
service to students. That is, because Black students can enroll in either HBCUs or HWIHEs, the HBCU may no longer serve its original purpose. Additionally, when it comes to working with local businesses and potential sponsors, Eleanor noted that businesses do not partner or donate to HBCUs because they are not seen as diverse and inclusive:

With society constantly questioning the purpose of HBCUs, local and even national vendors and businesses don't partner or donate to these institutions because they are not seen as diverse and inclusive. In comparison to [HWIHEs], I believe they have an easier task of marketing themselves, whereas HBCUs are playing catchup by fighting the stereotypes.

According to Eleanor, HBCUs needed to combat these stereotypes when trying to work with corporate partners.

History. When it comes to historical challenges facing HBCUs, three out of five participants mentioned that HBCU students are typically first-generation college students who come from backgrounds with little financial support. The discussion around the demographics of the students at HBCUs was consistent with previous research from Albritton (2012), Arnett (2014), and Bracey (2017). The consistency of this acknowledgment, coupled with the continued mention of the overall lack of resources stemming from the beginnings of these historic institutions, has led to the fiscal challenges facing HBCU athletic departments.

Administration. From an administrative perspective, three out of the five participants noted that HBCU athletic departments were understaffed. Penelope shared: "With the overworked staff comes lack of attention to detail." In this statement, she was referring to the unfortunate occurrence of HBCUs finding themselves in NCAA infraction cases.

From an athletic administrator perspective, participants mentioned how the athletic administers were out of touch with the college athletes. For example, Eleanor noted: "The student-athletes have given up hope in their administration, and it doesn't mean as much because athletes feel as though they are not a priority to their administration if they are not bringing in revenue." Theodore made similar mention of the emphasis placed on revenue sports at HBCUs. It could be surmised through the interviews that HBCUs might not be making the investment in non-revenue-generating sports and are losing out on revenue opportunities. Some potential revenue-generating opportunities that could come from non-revenue-generating sports include ticket sales and sponsorships. Although interviewees discussed these administrative challenges in the context of HBCUs, it is important to note that participants acknowledged similar fiscal challenges facing HWIHE athletic departments.

One notable similar challenge was getting the administration on board with athletics. The participants mentioned how athletics were dependent on what the institution wanted to do, including facility upgrades and scholarships. Additionally, Francis 
mentioned that it was often out of the hands of athletic administrators in the decision to add or remove a sport program.

Global Issues. Across the board, participants touched on the subtheme of global issues that emerged through the interviews. According to three out of five of the interviewees, the greatest challenge facing both HBCUs and HWIHEs across the board was enrollment. The participants explained that they believed HBCUs and their HWIHE peer institutions were enrollment driven and depended on revenue before allocating funds toward athletics. This discussion of relying on tuition is consistent with previous literature from Stewart (2017), who indicated that HBCUs are dependent on revenue from tuition. Eleanor commented on her time as a college athlete and encountering other athletes who faced similar issues at a HWIHE:

I encountered different student-athletes from various backgrounds that went through the same things and had similar problems in relation to scholarships or resources regardless of it we went to a [HWIHE] or an HBCU. Some of the schools' financial issues are not HBCU-specific.

One common mention from participants was how government cuts on education were impacting both HWIHE and HBCU campuses. Participants acknowledged the decline in state funding was a fiscal challenge facing NCAA member institutions across the board, and that athletic departments, in general, were starting to have to run themselves like a business. For example, they were facing increasing pressure to be self-sustaining and not rely on funds from the institution to support athletics. This discussion expands upon research from Arnett (2014) reporting government spending toward HBCUs has been decreasing.

Fan Experience. The impact of fan experience on athletic department finances was identified as an HBCU-specific issue. As Theodore mentioned regarding HBCUs historically providing the only opportunity for Black students when it came to college sport, now that HWIHEs are more accessible, HBCU athletic programs face much more competition today. Theodore outlined the financial implications of this challenge: "Fans naturally draw toward success, which is a natural thing, and that is just something I learned from working at an HBCU." From Theodore's statement, it could be surmised that HBCUs are still trying to attract the same fans they had when they produced professional athletes on a more frequent basis. Participants frequently mentioned that the fan experience at HBCU athletic contests was lacking, probably due to a lack of resources to invest in in-game productions. As a result of this lack of fan experience, fan attendance has suffered.

\section{Opportunities}

Opportunity was a common theme discussed during the interviews with independent participants. Through the interviews, the subthemes of marketing, strategic planning, and students emerged. In the following sections, each of subthemes is discussed in further detail. 
Marketing. The most common subtheme that emerged was marketing. Interviewees noted HBCUs were missing out on opportunities to engage with alumni. Pep rallies, digital advertising around a game, and working with local newspapers to advertise athletic events were suggestions made from participants. For example, Penelope explained that one of the HBCU athletic directors she works with often went into the community and simply told the story of her college athletes on campus - both about their success in the classroom and on the field. Penelope noted in her interview: "HBCUs in particular need to do a better job telling the story of their success of their student-athletes, on the field and in the classroom. Not just to alumni. [They] need to sell stories where they live and work." Her statement suggests that some HBCUs are not fully engaging with their community. Having an athletic director take the time to go out into the community could possibly help HBCU athletic administrators go beyond fundraising initiatives that rely solely on their alumni base and build relationships with corporate partners.

Beyond reaching out into the community to begin fundraising initiatives, the empirical material collected from the interviews suggested more community engagement and building a good fan atmosphere are key. Specifically, Theodore noted in his interview: "[Financially successful athletic programs] really cared about the aesthetics about their program, and it really created a comfortable atmosphere for their fans." In referring to aesthetics, the opportunity HBCUs have to use their athletic websites to market their athletic events was noted. When asked to compare HBCU and HWIHE athletic programs, one of the areas where HBCUs have the opportunity for growth is their athletic website. Having an updated website with scores, schedules, and locations of contests can help develop community and fan engagement. As described throughout the interviews, updating an existing website is a free opportunity for HBCUs to use that can increase fan engagement. Although it is commonly reported that HBCUs are leading in social media rankings (DII Social Media, 2018), the other area that participants indicated HBCUs could possibly improve was with their overall use of social media. Similar to the athletic department website, participants indicated social media is a free resource that some HBCUs are perhaps not taking advantage of to market their athletic programs.

Strategic Planning. The second most common theme that emerged related to opportunities was strategic planning. Having a better understanding of the overall athletic budget and working with external groups on campus were noted as opportunities that have helped peer campuses. As far as having a strategic plan, Francis noted that some NCAA member institutions are using athletics to enhance revenue:

Some institutions in our conference currently ... are using athletics to greatly enhance enrollment. They have very large squads, JV squads, and that is helping enrollment of the entire institution. We saw that in the membership committee where $75 \%$ of enrollment of an institution was athletics.

One of the important notes from the interviews was for the administration to understand what it costs to educate the students versus the cost of tuition. The gap in this figure could possibly help the institution allocate more dollars to athletics. Un- 
derstanding enrollment-based revenue can help increase numbers by adding junior varsity teams. For example, Eleanor noted how HWIHEs have used junior varsity teams to increase funding toward athletic programs: "I think [HWIHEs] allocated funds differently and on a more even platform as they have their JV teams that could support their primary sport programs."

Additionally, knowing the overall budget was noted as important for HBCUs athletic administrators. Francis mentioned that during her time as an athletic director on campus, it was necessary for her to know the entire athletic budget and even to make herself an important part of the institution's overall fiscal budget. This understanding would include being self-reliant and keeping spreadsheets of all revenues and expenses so that the institution's administration was clear on the athletic department's spending. Additionally, it was suggested that one of the most important things for HBCU athletic administrators was to make data-driven decisions when it came to managing the finances and being creative. For example, Eleanor mentioned the possibility of expanding master's programs and increasing graduate assistant positions in athletics to help fill some of the gaps created by the thin full-time staff. It was also noted that it is vital for the athletic director to be included in the president's council to provide guidance and information regarding athletics. Francis mentioned that even if the president did not take the advice of the athletic director, the athletic director would at least have advanced warning of any budget or sport program cuts.

When it came to relaying some of the fiscal challenges to the coaching groups, participants expressed the importance of being transparent with coaches. The participants noted that coaches could provide valuable insight as far as letting an athletic director know what they might be able to go without for a season if they knew funding toward the athletic department, in general, had been cut. Specifically, Francis noted: "When I worked with my coaches, they were often able to tell me, well this is an area that $x$..." Additionally, having a good relationship with the office of advancement on campus was recurring advice to HBCUs given throughout the interviews. One area of advancement that was noted as a key target moving forward for HBCUs was creating and growing endowments.

Students. Finally, in terms of opportunity, there was discussion throughout the interviews about using students to help with some of the fiscal challenges facing HBCU athletic departments. Participants noted the perceived importance of using students on campus to help with marketing the athletic programs. For example, Penelope mentioned that finding some good college-athlete representatives and putting them on the road to meet with the community members and alumni could be a great way to connect and share the athletic department's story. Olivia discussed that students on campus are another resource that athletic departments are not taking advantage of to deal with fiscal challenges, specifically staffing limitations:

I don't think that HBCUs use their students' talent to their advantage as many athletes are walking these campuses with the next best talent and instead of giving them the opportunity for growth with mentors in place, they resort to the safe methods of using whatever method they currently have in place. 
Olivia's statement suggests that many HBCUs may be missing out on using students on campus to help with marketing their athletic contests. As Theodore added, college athletes could even help with building media around the team. Using students was described as beneficial to HBCUs because students can bring talent, interest in athletics, and new perspectives. Additionally, it was noted that students on HBCU campuses are the best way to get information spread by word of mouth.

The overall sentiments from the independent perspectives suggested that although there are still fiscal challenges facing HBCU athletic departments, they may be getting better. In the next section, we discuss insider perceptions of fiscal challenges.

\section{Insider Perspective}

In the empirical material collected regarding fiscal issues from the insider participants four overarching themes were identified: culture, staffing, roadblocks, and solutions. The subthemes for each of these are discussed below.

\section{Culture}

Beginning with the theme of culture, the subthemes of perception, gameday, and advancement emerged. The sections below detail the findings offered by participants.

Perception. The most prevalent subtheme was perception. The participants acknowledged how there is a distrust in HBCUs and how funds are spent at the institutions. The participants reported they believed the distrust was rooted in how HBCUs are portrayed in the news, their fiscal management, and accreditation issues. From the discussion with participants, it could be gathered that they believe donors question if the funds given are being used for their intended purpose. Briel noted that HBCUs need to be more transparent with donors to help the situation "be truly transparent and honest about where our money is going and where it has gone in the past." Participants indicated that HBCUs need to keep donors updated on where money has gone to reduce uncertainty.

Although insider participants identified the distrust, Briel noted that it is important to understand that HBCUs were still tasked with trying to meet the same expectations as HWIHEs:

Everyone has the same expectations as [HWIHEs]. What people expect from us here is the same that they expect from [an HWIHE]. So, we try to keep up with what everyone else is doing, but we don't have the money to do it, so we end up going broke trying to chase what everyone else is doing.

Fitz acknowledged that although he believes there is a general interest in wanting to change the culture of HBCUs, he has not noticed any changes.

Gameday. From a gameday perspective, Josie indicated that although the game atmosphere at both a HWIHE and an HBCU differ, there is still a common goal. Specifically, Josie gave the following description of the difference in gameday atmosphere: 
HBCUs and [HWIHEs] have the same goal: they want their fans to come out and enjoy, they want the fans to be engaged, and they want them to return to the game because that will also help in revenue, hoping those fans become donors. So, I think the goals of the HBCUs and [HWIHEs] are the same, but the environment may be a little different. At an HBCU, you are going to have music; you are going to have dancers. The vibe of an HBCU game day is more of a party . . . [An HWIHE] is going to be more of an [enjoyable] evening, not so much of a party. But the goal for both is definitely the same.

Beyond the difference in atmosphere, four out of the five insider participants acknowledged the differences in facilities at HBCUs. The participants noted most HBCUs had a component of shared facilities, requiring teams to share practice and competition facilities with other teams in the department. Although it was acknowledged that a similar issue might exist at HWIHEs, it was more prevalent at HBCUs.

Finally, additional insight from participants included the lack of ability to generate ticket revenue and sponsorships. Finn acknowledged HBCU conferences have been leading in football attendance, but he was not sure how that attendance is turning into generated revenue: "While the SIAC (Southern Intercollegiate Athletic Conference) has been leading conferences in football attendance over the last 10 years, I still am a little skeptical in the sense that we are able to generate the kind of ticket revenue and sponsorships that offset the cost that comes with running competitive programs." The lack of correlation between attendance and reported ticket revenue provide additional evidence of some of the distrust noted by participants in HBCUs.

Advancement. Four out of the five participants noted the culture of alumni giving at HBCUs does not help athletics. Finn detailed the situation:

The differences between HBCUs and [HWIHEs] that are the same size is most of the [HWIHEs] have a history of philanthropy and have worked with alums and friends of the university to provide more discretionary dollars that go back into the athletic program. The history of philanthropy is not the same at HBCUs.

The insider participants indicated that changing this culture would have to start with alumni. However, participants observed a difference in the type of alumni that graduate from these institutions. For example, participants noted that alumni at HBCUs are not graduating with degrees that have high earning potential in the first couple of years after graduation. The insider participants indicated that this low level of giving from HBCU alumni could only help support tuition so far. However, participants did note they saw the outlook on alumni giving getting a little better. Still, Briel shared: "We do not do a lot of asking from alumni, once we get told no, we do not want to ask again. Whereas I am a HWIHE graduate and they ask almost every day for something." Overall, there was a positive outlook on the projection of alumni giving compared to previous years, but participants indicated it needed to improve. 
Under the culture of endowments at HBCUs, participants indicated HBCUs do not have healthy endowments compared to HWIHEs. Specifically, Finn noted: "Our endowment is under $\$ 10.8$ million, so you are not generating the residual income that can be used to offset the cost of running a competitive program." Insider participants echoed these concerns with low endowments at HBCUs and how the athletic departments had limited pull with the institution to help the athletic department financially. The next section outlines staffing issues and participants' perception of their impact on fiscal challenges.

\section{Staffing}

Under the theme of staffing, the subthemes of staff make-up, the need for development specialists, and professional development emerged. Each subtheme is discussed in the sections below.

Staff Make-Up. Beginning with the staff make-up, the insider participants mentioned that HBCUs need to hire people that understand the culture of an HBCU because they reported HBCU employees wear multiple hats, and there are fewer people in each department doing the work of similar size institutions. Briel mentioned the most important thing for a new hire at an HBCU is for them to understand the culture. Josie echoed this recommendation: "You don't want to get caught up with 'We don't have this, or we should be doing this.' It is almost like you need to embrace what you have and figure out ways to get what you need."

An additional concern outlined by participants was staff turnover and how it could impact financial challenges. For example, Fitz outlined his experience:

The turnover does not help in a lot of scenarios. For example, you know the first day I started here, the athletic director that hired me was let go the next day by the president. Two days later, the president who let go the athletic director was gone, so in a two-to-three day span, there were two new leaders in big-time roles at the school. So, even if there was a plan in place to do something along these lines, it quickly got [dropped] because you had new leadership immediately.

The turnover mentioned by Fitz complements previous research from Quarterman (1992) addressing the high staff turnover rate at HBCUs. Beyond turnover, the limited staff in the different departments of athletics was also noted by participants. Specifically, Josie mentioned how academic advisors were not as prevalent in HBCU athletic departments, and the lack of advising and tutorial centers could impact the students. Josie's statement expanded upon previous research by Bannister (2014) that indicated the lack of academic resources on HBCU campuses. The insider participants described how the multiple hats worn by HBCU athletic administrators prevented advancement, as one person had multiple duties, some of which included fundraising. The next section specifically details the insiders' perception of advancement employees at HBCUs. 
Need for Development Specialists. Insider participants acknowledged the lack of athletic associations or booster clubs to help supplement athletic programs. Finn mentioned that one of the first things he did when he began his current position at an HBCU was to hire a development person who only raised money for athletics. From the discussion with participants, it appeared as there was increased pressure on athletic directors at HBCUs to raise money in addition to their responsibility of running the athletic department. Fitz mentioned that the lack of development personnel was where he believes HBCUs are failing. The participants mentioned the importance of hiring someone whose sole priority was to raise funds for the department of athletics. Additionally, participants mentioned the importance of the investment of hiring the individual to focus only on development for athletics.

Professional Development. The insider participants mentioned the lack of professional development for employees of HBCUs. Josie acknowledged that funding might provide the rationale for the limited professional development opportunities: "Professional development, at HBCUs . . it is not that it is hard to find. I think there are really good professional development opportunities. I think it goes back to funding and being able to bring back good takeaways." Lynn and Briel both mentioned professional development opportunities created by the NCAA for minorities.

One common discussion topic amongst participants regarding professional development and how it created fiscal challenges was the problem of current employees becoming set in their ways. Briel mentioned that a lot of people working at HBCUs have been there for years and were graduates of the institutions, so that is the only thing they knew. Participants mentioned the challenge faced by HBCUs when outsiders were hired to work on campus and make changes to benefit the institution. Additional challenges and roadblocks facing HBCUs and their attempt to overcome fiscal challenges are outlined in the next section.

\section{Roadblocks}

Under the theme of roadblocks, the subthemes of operating costs and finances emerged. The following sections offer the findings associated with each subtheme.

Operating Costs. From an operational perspective, participants mentioned how travel to play games was getting expensive, especially with expanding HBCU athletic conferences. Finn noted how many HBCU conferences included schools outside of their geographic region, making travel costs rise. Additionally, one of the other operational roadblocks mentioned was carrying non-revenue-generating sports to ensure compliance with Title IX. Institutions are required to comply with Title IX, and if additional funding is added to support the revenue-generating sports of men's basketball and football, corresponding funding and athletic opportunities need to be provided to women college athletes as well. These additional funds and opportunities could potentially create new budget challenges. 
Funding. From a funding perspective, participants discussed the lack of funding that impacted staffing, facility updates, and scholarships for college athletes. However, it was noted by participants that these challenges were consistent with similarly sized HWIHEs. According to interviewees, challenges unique to HBCUs were low enrollment, low retention, and the necessity for the majority of students to be on some type of financial aid. Participants acknowledged how these challenges impacted their operating budgets in athletics and limited the number of discretionary dollars available to athletics. To address some of these issues, participants offered several solutions, the final emerging theme.

\section{Solutions}

Under the theme of solutions, the subthemes of strategic planning and fundraising emerged. Each subtheme is discussed in detail in the sections below.

Strategic Planning. Beginning with the subtheme of strategic planning, participants mentioned that they believed HWIHEs typically create and follow through on strategic plans more consistently compared to most HBCUs. Specifically, Josie mentioned:

I think we have them (strategic plans) at HBCUs. I think in some cases we need to revisit them throughout the year to try and make sure we are staying on task with what it is we are trying to do for our athletic programs and in what ways athletics is helping to support the institution.

Participants indicated that HBCUs need to define goals and tasks specifically. Briel mentioned that strategic planning might include reevaluating what sports HBCU athletic departments are sponsoring.

When participants were asked if they believed these fiscal issues were improving on the campuses of HBCUs, several participants responded that they thought steps were being taken to improve some of their challenges. For example, Briel acknowledged that "under our current administrative leadership here, our president has placed an emphasis on managing the fiscal budget more responsibly and that is something that has been a tremendous help for the institution as a whole here." Participants mentioned the need for athletic administrators to begin to use any revenue they do generate more efficiently and effectively.

Fundraising. When it comes to fundraising, three out of five participants believed more capital campaigns could help athletic departments and institutions facing fiscal challenges. Participants mentioned that it was important for these capital campaigns to happen at the right times and ensure there was a method to the campaigns with clear goals. The importance of customer service when fundraising was also highlighted by participants. For instance, Josie mentioned that for both HBCUs and HWIHEs, "because that customer service, even with your student-athletes, as well as fans and sponsors, those are the things that have people continuing to come 
back and support your program." The relationship with donors was highlighted by all participants, making sure athletic administrators were asking for what they truly needed and being transparent with where the money is going.

\section{Summary}

Both independent and insider participants acknowledged that the history of HBCUs was a fiscal challenge impacting the athletic department. Specifically, participants noted how there was not a strong culture of alumni giving at many HBCUs. Additionally, when it came to fiscal challenges, staffing issues in HBCU athletic departments were heavily highlighted by participants. Specifically, they indicated that HBCUs were not investing in (or lacked the means to invest in) hiring specialists that could focus on generating funds for the athletic department.

\section{Discussion}

Overall, the findings indicated fiscal issues as unique to HBCUs. The fiscal issues exemplify the lack of resources faced by HBCU athletic departments. As Cheeks (2016) explained, the lack of resources at HBCUs extend to older athletics facilities and contribute to a lack of staffing. Furthermore, based on resource dependency theory, this scarcity of resources may limit the power and influence of HBCUs, as the institutions may rely on external stakeholders to provide funding for program success. These limitations may be experienced by individual colleges or universities; furthermore, they may threaten HBCUs as a broader institution of higher education, thereby necessitating collaborative strategies across institutions.

Cheeks (2016) offered the solution of HBCUs working together as a conference to pull resources. This proposed solution has proven successful through conference-wide apparel partnerships at the SIAC. Further exploration may determine if it is possible for the conference to share staff. Perkins (2018) called for HBCUs to prioritize and allocate funds to support college athletes' academic success. It might be possible for a governance structure to include the conference office employing an individual to help each institution oversee academic support for athletes on campus. Another example might include hiring a development employee at the conference office for the purpose of helping individual member institutions create fundraising campaigns. Although a possible solution, this suggestion relates back to resource dependency theory as the institutions would become more dependent on the conference office and possibly lose decision making power.

One challenge highlighted in this study included the culture of alumni giving at HBCUs. This result expands upon previous research from Stuart (2017), suggesting potential donors do not appear to be making the investment in HBCUs. Previous research has found a connection between athletic success and financial contributions from private donors (Walker, 2015). The results of the current study extend these findings to HBCUs as they relate back to resource dependency theory because the institutions are dependent on their external stakeholders for financial contributions and may need to adjust athletic department strategies to meet the motives of external 
stakeholders. However, it should be noted that even though this study indicated there is not a strong giving culture in place on HBCU campuses, participants agreed that HBCUs were not putting the best fundraising and institutional development practices in place to improve the financial outlook for the institution. This finding supports previous literature indicating HBCUs are not hiring marketing or external relations employees (Jackson et al., 2001; Li \& Burden, 2009). The lack of marketing or external relation employees possibly indicates that some HBCUs might not be selling the story of their institutions. As Salancik and Pfeffer (1977) indicated, organizations will compete for resources that are in scarce supply. With no marketing or external relation employees to lead fundraising efforts, HBCUs might continue to lose already-scarce fundraising dollars to peer institutions thus reflecting resource dependency theory.

From an administrative perspective, participants in the current study indicated that staff at many HBCUs are overworked and may not necessarily be the right fit for their positions. Staff can serve as crucial resources for institutions. Salancik and Pfeffer (1977) indicated the resources an organization has determines its overall power; thus resource dependency theory is reflected in the overworked administration. This finding indicates HBCUs may benefit from the NCAA publishing recommended guidelines to include minimum qualifications and job requirements for necessary positions in the athletic department. As HBCUs might have limited funding for search committees, best practice documents can be used as a free resource to help the institutions ensure proper hires. The NCAA Division II Athletic Director Association currently publishes a Model Athletic Department Document. Expanding this document to include suggested education and experience recommendations for various positions could prove helpful. For example, it would be helpful for the Director of Athletics position to require a successful fundraising background. Coupet (2013) indicated it might be helpful for HBCUs facing limited resources to hire leaders, such as Athletic Directors and Presidents, who might not have as relevant experience in HBCU governance, but have an understanding of the "organizational behavior with the resource environment, and who have familiarity with the diverse resource pools that the organization might find attractive" (p. 366). When staffing, it might prove helpful for search committees to look beyond HBCUs for employees.

Additionally, HBCU employees were not receiving adequate professional development opportunities. The lack of professional development opportunities could contribute to the stagnant work cycle at HBCUs, preventing the institutions from employing innovative solutions to address the fiscal challenges they face on campus. However, although administrators reported a sense of a lack of professional development opportunities, Johnson (2013) indicated that the NCAA has been responsive to the challenges facing HBCUs and has implemented programming to provide professional development opportunities. Specifically, the research from Johnson (2013) highlighted the Supplemental Support Fund program established by the NCAA to provide professional development to enhance college athletes' academic performance. Expanding upon current professional development opportunities offered, the NCAA could provide more relevant opportunities to meet the needs of HBCU athletic employees. These opportunities could include conferences and symposia re- 
lated to best practices in marketing, fundraising efforts, and fiscal management in athletics. However, as mentioned previously, if HBCUs continue to depend on the NCAA or other governing bodies for resources, they might jeopardize decision-making power in the NCAA membership.

The HBCU campus culture was another area discussed by participants. The discussion implied that there is an internal conflict within HBCUs around the original mission and purpose of educating Black students, and how the purpose of HBCUs has evolved over time. The result of this change has led to shrinking enrollment and thus less revenue from tuition (Camera, 2017). As HBCUs are predominantly funded through tuition, the lack of enrollment directly impacts the budget for the institution and creates fiscal challenges and supports the theme of resource dependency theory. However, as stated by Lockett (2017), HBCUs play a role in educating a diverse body of students that might not have had the access to HWIHEs. Lockett recommended policy makers and higher education experts collaborate to determine the value offered by these institutions when determining financial allocation to these institutions.

Relating to revenue opportunities, specifically game guarantees, it is important for HBCUs to capitalize on the details of signed contracts. For example, some HBCU football teams that participate in annual football classics receive additional bonuses for increased fan attendance at games. Classics are traditionally neutral site events that involve more than just the football game between two HBCUs; the classics include events such as the battle of the bands, step shows, and parades. According to Lillig (2009), Florida A\&M University receives a $\$ 25,000$ bonus to their contract with the Circle City Classic if they exceed 57,000 people in attendance. Taking advantage of these contract incentives can help HBCUs increase revenue for their athletic department.

When discussing possible solutions to the fiscal challenges facing HBCUs, participants indicated that HBCUs are not participating in strategic planning. Additionally, from a fundraising standpoint, HBCUs could do more work on the advancement side with capital campaigns and building endowments. This finding echoes the need highlighted by Lee and Keys (2013) for HBCUs to find creative ways to increase revenue by cultivating relationships with alumni and other partnerships. The findings of this current study suggested that HBCUs are working toward building endowments and initiating capital campaigns. This result expands upon previous research from Gasman (2009) that indicated HBCUs have small endowments, thereby limiting funding for their campus. These initiatives could help HBCUs counter fiscal challenges faced by their institution and put them on a more even financial playing field.

As suggested by Cooper et al. (2014), it could be advantageous for HBCU athletic departments to work collectively to prevent oppression in the NCAA structure. This could mean strategizing as a collective unit when pursuing conference wide contracts. For example, the SIAC continues to make conference-wide deals at the benefit of their individual member institutions. Combining resources could help strengthen the power HBCU member institutions have within the NCAA structure. 


\section{Concluding Remarks}

In light of the findings of this study, it is important that future research continues to find ways for HBCUs to capitalize on revenue generation and strategic planning to help make the best of the limited resources these institutions have for the athletic departments. From a strategic planning perspective, it is important that future research looks into the best practices that peer institutions have already implemented to understand what practices might work for HBCU athletic administrators. Research to guide staff members at HBCUs can assist in determining the best practices for their institutions. Specifically, research analyzing college-athlete experience, operations, travel, scholarships, and fundraising can aid athletic administrators already spread thin with developing a strategic plan that can be immediately impactful in their athletic department. Additionally, future research could aid in comprehending the cultural dynamics that HBCU athletic departments have to sell to corporate sponsors and alumni.

Overall, the findings of this study indicate that HBCU athletic departments have potential. All participants in this study indicated that HBCU athletic departments have a great product and story to sell when endeavoring to generate additional revenue. Acknowledging the historical fiscal challenges may prove beneficial when conveying revenue generation proposals to sponsors, donors, and alumni. Once the stories are told, it will be interesting to watch the development of revenue generation capabilities, and how these underfunded institutions might be able to capitalize on additional revenue streams that they are currently not taking advantage of in their athletic departments.

\section{References}

2019 a. Division II Second Publication of Proposed Legislation. Retrieved from https://web3.ncaa.org/lsdbi/reports/getReport/90005

Albritton, T. J. (2012). Educating our own: The historical legacy of HBCUs and their relevance for educating a new generation of leaders. Urban Review, 44, 311-331.

Arnett, A. (2014, December 18). State of HBCUs. Retrieved from www.diverseeducation.com

Auerbach, N. (2016, March 15). Successful HBCU basketball coaches endure rockier climb. USA Today. Retrieved from https:/www.usatoday.com/story/sports/ ncaab/meac/2016/03/15/successful-hbcubasketball-coaches-endure-rockier-climb-hampton-meac/81820174/

Bannister, N. (2014, April 10). Ghosts of athletics past haunt HBCUs. Diverse: Issues in Higher Education. Retrieved from https://www.questia.com/magazine/1G1-366082695/ghosts-of-athletics-past-haunt-hbcus

Bozeman, B., \& Faye, D. (2013). Minority football coaches' diminished careers: Why is the "pipeline" clogged? Social Science Quarterly, 94, 29-58. 
Bracey, E. (2017). The significance of historically black colleges and universities (HBCUs) in the 21st century: Will such institutions of higher learning survive? American Journal of Economics \& Sociology, 76, 670-696.

Brinkmann, S. (2013). Qualitative interviewing. Oxford: Oxford University Press.

Brod, M., Tesler, L. E., \& Christensen, T. L. (2009). Qualitative research and content validity: Developing best practices based on science and experience. Quality of Life Research, 18, 1263-1278.

Camera, L. (2017). Keeping a promise to HBCUs. U.S. News. Retrieved from http:// eds.a.ebscohost.com/eds/pdfviewer/pdfviewer?vid=4\&sid=b59e063f-9739-46b 1-8b1b-1c29faad471a\%40sessionmgr4009

Cheeks, G. (2016). A Critical Examination of NCAA Division I HBCU Athletic Director's Perspective of the Current State of Intercollegiate Athletics (Doctoral dissertation).

Cheeks, G., \& Carter-Francique, A. R. (2015). HBCUs versus HWCUs: A critical examination of institutional distancing between collegiate athletic program. Race, Gender \& Class, 22(1-2), 23-35.

Cianfrone, B. A., Pitts, B. G., Zhang, J. J., Byrd, C., \& Drane, D. D. (2010). A market segmentation analysis of historically Black college and university "Classic" attendees. Presentation at the 2010 North American Society for Sport Management conference.

Cooper, J. N., Cavil, J. K., \& Cheeks, G. (2014). The state of intercollegiate athletics at historically Black colleges and universities (HBCUs): Past, present, \& persistence. Journal of Issues in Intercollegiate Athletics, 7, 307- 332.

Cooper, J. N., \& Dougherty, S. (2015). Does race still matter?: A post bowl championship series (BCS) era examination of student athletes' experiences at a Division I historically Black college/university and predominantly white institution (PWI). Journal of Issues in Intercollegiate Athletics, 8, 74-101.

Cooper, J. N., \& Hawkins, B. (2012). A place of opportunity: Black male student-athletes' experiences at a historically Black university. Journal of Intercollegiate Sport, 5, 170-188.

Cooper, J. N., \& Hawkins, B. (2014). The transfer effect: A critical race theory examination of Black male transfer student-athletes' experience. Journal of Intercollegiate Sport, 7, 80-104.

Cooper, J. N., Porter, C. J., \& Davis, T. J. (2017). Success through community cultural wealth: Reflection from black female college athletes at a historically Black college/university (HBCU) and a Historically White Institution (HWI). Journal of Intercollegiate Sport, 10, 129-156.

Coupet, J. (2013). Historically Black colleges and universities and resource dependence: a Chow test of production functions. Journal of Higher Education Policy and Management, 35(4), 355-369.

Crotty, M. (1998). Foundations of social research: Meaning and perspective in the research process. Thousand Oaks, CA: SAGE.

DII Social Media. (2018). Retrieved from http://d2socialmedia.com/list/conf/ 
Elliott, K. P., \& Kellison, T. (2018). Assessing spectator response to sport sponsorships at historically black colleges and universities. Journal of Applied Sport Management, 10, 22-33.

Elliott, K. P., Kellison, T., \& Cianfrone, B.A. (2019). Budgeting for success: Comparing finances between historically black colleges and universities and predominantly white institutions. Journal of Intercollegiate Sport, 12, 25-42.

Gasman, M. (2009). Historically black colleges and universities in a time of economic crisis. Academe, 9, 26-28.

Hancock, D. R., \& Algozzine B. (2017). Doing Case Study Research: A Practical Guide for Beginning Researchers. Teachers College Press, New York.

Jackson, E. N., Lyons, R., \& Gooden, S. C. (2001). The marketing of black college sports. Sports Marketing Quarterly, 10, 138-146.

Johnson, M. N. (2013). Financial and related issues among Historically Black Colleges and Universities. Journal of Intercollegiate Sport, 6, 65-75.

Jones, W. (2015). Do college rankings matter? Examining the influence of "America's Best Black Colleges" on HBCU undergraduate admissions. American Journal of Education, 247- 265..

Lee, J. M., \& Keys, S. W. (2013). Repositioning HBCUs for the future: Access, success, research, \& innovation. APLU Office of Access and Success Discussion Paper 2013-01. Washington, DC: Association of Public and Land-grant Universities.

Lillig, J. (2009). "Magic” or misery?: HBCUs, guarantee contracts, and public policy. Journal of Sports Law \& Contemporary Problems, 6(41), 41-71.

Li, M., \& Burden, W. (2009). A survey of the sport marketing and sponsorship practices of Historically Black Colleges and Universities (HBCUs) playing NCAA Division I Football. Presentation at the 2009 North American Society for Sport Management.

Lockett, A. W. (2017). Examining performance-based funding and historically Black colleges: Unequal footing. In: Educational challenges at minority serving institutions (pp. 36-51). Routledge, United Kingdom.

National Collegiate Athletic Association. (2018). Retrieved from http://www.ncaa. org/about/where-does-money-go

Perkins, L. (2018). An examination of Historically Black Colleges and Universities' (HBCU) intercollegiate athletic directors' utilization and effectiveness of resources to foster student-athlete academic success: A comparative case study analysis. Doctoral dissertation, Delaware State University.

Quarterman, J. (1992). Characteristics of athletic directors at historically black colleges and universities. Journal of Sport Management, 6, 52-63.

Robbins, G., Gilbert, J., \& Clifton, A. (2015). Coaching stressors in a Division II historically black university. Journal of Intercollegiate Sport, 8, 183-205.

Salancik, G. R., \& Pfeffer, J. (1977). Who gets power - and how they hold on to it. Organizational Dynamics, 5, 3-21.

Savage, G. (2017). An uncertain future of the nation's oldest HBCU. Diverse Issues in Higher Education, 34, 21-22. 
Stuart, R. (2017). Financial anxiety. Diverse Issues in Higher Education, 34, 10-11. Taylor, S., Bogdan, R., \& Devalut, M. L. (2016). Introduction to qualitative research methods: A guidebook and resource. Oxford: Oxford University Press.

Trahan, T. (2012). Hampered by small budgets and larger institutional problems, once-proud HBCU football programs are Division I competitors in name only. Would they be better off dropping down to Division II? Vice Sports. Retrieved from https://www.vice.com/en/article/yp8vg7/should-grambling-state-southern-hbcus-drop-division-i-football

Ulrich, D., \& Barney, J. B. (1984). Perspectives in organizations: Resource dependence, efficiency, and population. Academy of Management Review, 9, 471-481.

Walker, A. (2015). Division I intercollegiate athletics success and the financial impact on universities. Sage Open, 1-13. 